\title{
Plágio e pirataria na academia: entre Mizner e o Código Penal Brasileiro
}

Prof. Dr. Hélio ARThur Reis Irigaray ${ }^{1}$

${ }^{1}$ Fundação Getulio Vargas / Escola Brasileira de Administração Pública e de EMPRESAS, Rio de Janeiro - RJ, BRASIL

Certa vez o dramaturgo estadunidense Wilson Mizner afirmou: “[...] se você rouba ideia de um autor é plágio. Se você rouba de muitos autores, é pesquisa" (BRAINY QUOTES, 2020); já para o Código Penal Brasileiro, independentemente do número de fontes, plágio é crime; pois roubar uma ideia equivale a roubar um bem.

Ao longo da minha vida profissional na academia, um dos maiores desafios que tenho enfrentado é julgar e avaliar a falta de marcas autorais nos trabalhos apresentados pelos alunos e pares. Teriam sido produto de má-fé ou mero desconhecimento das normas acadêmicas?

A similaridade com textos previamente produzidos, sem que estes tenham sido devidamente referenciados, não se limita mais apenas a trabalhos de disciplinas, monografias ou trabalhos finais de curso de pós-graduação lato sensu. Infelizmente, o mesmo tem ocorrido em dissertações, artigos submetidos a periódicos e, até, em teses.

A facilidade de acesso a informações, principalmente as disponibilizadas por meio eletrônico (internet), permite, muitas vezes, sua reprodução indevida, ou o que podemos chamar de "cópia", sem as devidas citações autorais, caracterizando plágio (GALVÃO, 2014).

Alguns tipos de plágio ocorrem em diferentes áreas de conhecimento, artes etc. O plágio integral, como o próprio nome já diz, é a cópia fiel de partes de uma obra sem a sua citação ou o referenciamento; o plágio parcial seria uma miscelânea de partes de textos ou frases de um ou mais autores sem especificar a fonte; o plágio conceitual, o uso das ideias ou a reescrita sem a devida citação e referência ao conteúdo original; e o autoplágio, muito comum entre autores de artigos acadêmicos, alunos de mestrado e doutorado, que utilizam as suas próprias produções acadêmicas (estudos anteriores) de forma total ou parcial para a produção de novas pesquisas e conteúdos sem referenciar estes trabalhos precedentes (GALVÃO, 2014).

O plágio, na sua essência, fere a integridade da academia, os códigos de conduta das instituições e, no limite, a credibilidade dos periódicos e de toda a comunidade científica.

Apesar das campanhas de comunicação e conscientização e das estratégias de prevenção adotadas pelas instituições de ensino e periódicos, a cópia ilegal de textos, gráficos e ideias ainda é uma prática bastante comum, quando não deveria ser (GASPARYAN, 2016).

Como professor, orientador, membro interno e externo de bancas, tenho encontrado com frequência trabalhos sem marcas autorais. $\mathrm{O}$ mesmo tem ocorrido como editor-chefe deste periódico. Tendo a creditar a intensificação destas ocorrências à expansão do acesso aberto (open access) e ao aumento da cobertura de periódicos por meio de banco de dados bibliográficos globais.

Com o objetivo de identificar "plágios" e coibir a sua prática, ferramentas como Turntin, Ithenticate, Plagiarism Detector, Plagius, Ephorus, Iplag, Scribber, NewJester e Farejador de Plágio foram desenvolvidas e são comumente usadas.

Acima, usei aspas propositalmente; pois, um dos objetivos deste editorial é a reflexão sobre o que é plágio. Mais do que isso, é um convite a repensarmos juntos nosso papel como editores, avaliadores e professores.

Nestes últimos anos, como editor-chefe do Cadernos EBAPE.BR, deparei-me com quatro artigos que poderiam ser considerados plágio, se levássemos em conta apenas o índice de similaridade apresentado pelo Ithenticate. Todavia, eram trabalhos de pesquisadores conhecidos na academia, com produção relevante em suas áreas. O que teria ocorrido? 
Bem, por definição, plágio está associado: a) a trabalho produzido por outrem como se fosse de quem o apresentou; b) à cópia de palavras, gráficos ou ideias de outra pessoa sem o devido crédito; c) à não citação, direta ou indireta, da fonte original; d) ao fornecimento de informações incorretas sobre uma fonte de referência; ou ainda, e) à modificação de palavras, mas com a estrutura do texto mantida, sem que seja creditada a fonte original (LOOI, WONG e KOH, 2015).

A rigor, podemos categorizar plágio em sete diferentes categorias: a) total; b) parafraseado; c) literal; d) colcha-de-retalhos; e) fantasma; f) autoplágio; g) ignorante.

O plágio total caracteriza-se pela apropriação de um trabalho produzido por terceiros. Aqui há duas possibilidades: a primeira, conhecida como ghost-writing, diz respeito a texto encomendado por meio de uma transação comercial; a segunda, à produção em grupo, quando, na verdade, um (ou mais) dos coautores em nada contribuiu.

O plágio total é o mais grave de todos, pois revela má intenção e falta de ética de todos os envolvidos. Como identificar que o(a) aluno(a) realmente produziu aquela obra? Como se certificar de que um trabalho em grupo efetivamente tenha contado com a participação de todos os componentes? Eis um grande desafio para todos nós.

Entendo que, quando este tipo de plágio é identificado, os envolvidos devam ser denunciados, responder criminalmente pelos seus atos e ser severamente punidos.

O segundo tipo de plágio, que chamamos de parafraseado, ocorre quando o autor reescreve outros textos em suas próprias palavras, sem que a fonte original seja citada, mesmo que esteja em outra língua. Cabe uma reflexão: houve um esforço genuíno para ser original ou foi uma trapaça?

Quero crer que, na maioria das vezes, um pesquisador júnior acredite que parafrasear é ser original, por estar buscando usar suas próprias palavras. No entanto, permanece ainda a possibilidade de que haja má intenção; de que a paráfrase seja apenas um instrumento - inócuo - de burlar os softwares antiplágio. Aqui, obviamente, cabe uma penalização.

Já o plágio literal, também conhecido como "copia e cola", é caracterizado pela cópia de um (fragmento de) texto, sem que ele seja referenciado. Neste caso, se a estrutura ou a maioria das palavras é reproduzida ipsis litteris, há um delito, ainda que se troque uma ou outra palavra. Quando desejamos fazer uma citação direta, devemos usar aspas e, obviamente, referenciar a fonte original.

O quarto tipo de plágio, que chamamos de colcha de retalho, ou mosaico, ocorre quando se combinam textos, frases, trechos ou ideias de diferentes fontes, sem que sejam devidamente citadas, visando à construção de um novo texto, aparentemente original.

Neste caso, também está incluído o uso de pequenas paráfrases, mesmo que a estrutura central original seja preservada. Felizmente, este tipo de delito é facilmente detectado pelos softwares. Entendo que, nestes casos, nem sempre há má intenção do(s) autor(es) e, quando isto ocorre, como editor-chefe, professor ou avaliador, solicito que o trecho seja reescrito.

Cabe ressaltar que, nos trabalhos acadêmicos, ao construirmos e apresentarmos um marco teórico, devemos ter em mente que não se trata de uma seção na qual são apresentadas infinitas citações, sem encadeamento e discussão (name dropping); mesmo que todos os autores tenham sido referenciados. Diante disso, nós, professores, orientadores e pareceristas, devemos atentar-nos menos aos rigores formais da formatação, a qual é facilmente corrigida, e focarmos mais nas reflexões críticas apresentadas e debates levantados por quem escreve o texto.

A quinta categoria refere-se ao plágio fantasma; ou seja, quando há a inclusão de textos que sequer foram consultados (ARÉVALO, 2020).

Há, ainda, uma questão mais sensível: como julgar quando um autor reproduz trechos ou ideias de um ou mais trabalhos que ele já tenha submetido a publicação?

Há quem defenda, por um lado, que esta prática seja inerente ao processo de pesquisa científica; que autores como Berger, Luckmann, Bauman, Arendt, entre tantos, revisitaram suas próprias obras, ideias e teorias para aprofundarem seus argumentos. Por outro lado, grande parte da academia advoga que esta prática, chamada de autoplágio, seja desonesta, pois parte do texto não é original.

Entendo que ambos os argumentos estejam corretos, dependendo da circunstância. Por exemplo, se um aluno submete o mesmo trabalho em diferentes disciplinas; se um autor submete artigos muito similares, em termos de argumentos, procedimentos metodológicos e resultados, diferenciando-os apenas por meio de paráfrases, podemos afirmar que, por um 
lado, de fato, houve má-fé. Por outro lado, quando resgatamos nossas próprias pesquisas, já publicadas, com o objetivo de aprofundarmos o debate, trazer novas evidências ou, até mesmo, nos contradizermos, então estamos colaborando com o avanço do campo. No limite, há uma genuína contribuição acadêmica. Este limite tênue entre o louvável e o reprovável exige das instituições de ensino, associações e periódicos a formulação de políticas específicas, que esclareçam o quanto e quando a autocitação é aceitável.

Por último, há o plágio decorrente da ignorância quanto às normas da academia ou até mesmo do desleixo, que ocorre quando não se fornecem todas as informações necessárias sobre a fonte utilizada.

Acho compreensível que este tipo de equívoco ocorra nas disciplinas de graduação e até de pós-graduação; mas é inadmissível encontrá-lo em um trabalho de final de curso, em qualquer nível; pois, quando ocorre, desvela negligência do orientador, que deve ser responsabilizado. Obviamente, por não ser tão grave, quando ocorre num artigo submetido a um periódico, cabe ao editor que exija os devidos ajustes.

Estas sete categorias de plágio, em todas as suas diferentes gradações de gravidade, são desafios a serem enfrentados. Todavia, há uma ameaça invisível, muito maior, muito mais grave, que tem sido pouco discutida: a pirataria intelectual. Esta não é fácil de ser detectada pelos softwares e demanda dos editores, avaliadores e professores um olhar muito atento ao texto relativamente ao objeto que está sendo discutido.

Um pirata intelectual é astuto o suficiente para produzir um texto aparentemente genuíno; ou seja, não há paráfrases, as citações são bem feitas, o índice de similaridade de seu trabalho é baixo. Então, onde estaria o crime?

Ele se apropria do que há de mais relevante em um estudo: a ideia, a sequência lógica, o encadeamento do raciocínio. Aí há a verdadeira violação dos direitos autorais.

Na ordem jurídica do Brasil, o plágio é tratado na Constituição Federal, na Lei dos Direitos Autorais N. 9.610/98, na Lei sobre Programas de Computador N. 9.609/98, na Lei N. 6.533/78 - regulamenta a profissão de artistas -, no novo Código Civil e nos decretos 75.699/75 e 76.905/75 - promulgaram as Convenções Internacionais de Berna e Genebra - , no Decreto 1.355/94 expediu o Tratado sobre os Aspectos dos Direitos de Propriedade Industrial relativos ao comércio (ABRÃO, 2014; COSTA, 2016).

Por isso, devemos estar alertas, visto que nem o mais poderoso dentre todos os softwares detectores de plágio e similaridades de textos é capaz de reconhecer e identificar piratarias intelectuais.

Não há mais como varrermos a poeira para debaixo do tapete. Há um elefante no meio da sala e não adianta fingirmos que não o estamos vendo. É hora de juntos debatermos as origens, métodos e consequências destas práticas desonestas de produção de textos. Não podemos permitir práticas corporativistas, sob pena de arriscarmos a credibilidade da academia e da ciência como um todo.

Apesar do espinhoso tema deste editorial, temos boas notícias: os artigos são originais e instigantes; eles nos convidam a refletir sobre as mais diversas áreas da Administração e construir desafiadoras sinapses.

Com o primeiro artigo, "Acumulação de capacidades tecnológicas inovadoras na indústria de defesa em economias emergentes: a experiência dos projetos REMAX e TORC30 no Exército Brasileiro", Luiz Henrique Abreu Dal Bello, Paulo N. Figueiredo e Thainá Ballero dos Anjos de Almeida examinam o processo de acumulação de capacidades tecnológicas para inovação e o papel dos processos subjacentes de aprendizagem tecnológica no contexto dos projetos Reparo de Metralhadora Automatizado X (REMAX) e Torre Operada Remotamente e Estabilizada para Canhão 30mm (TORC30) do Exército Brasileiro (EB), durante o período de 1999 a 2016.

Em "Pesquisa acadêmica e avanços em Ciência, Tecnologia e Inovação (CT\&I): uma proposta de aproximação pela Design Science", Donizeti Leandro de Souza, Thais Assis de Souza e Andre Luiz Zambalde apresentam um ensaio teórico que reflete sobre a utilização da Design Science como abordagem capaz de contribuir para uma aproximação das pesquisas acadêmicas com as atividades de Ciência, Tecnologia e Inovação (CT\&l), alinhando os esforços da academia às necessidades da sociedade.

Em seguida, Adonai José Lacruz tece “Considerações teóricas sobre governança corporativa no terceiro setor à luz da teoria da agência", revisitando a literatura sobre governança corporativa em organizações não governamentais (ONGs) sob a perspectiva analítica da teoria da agência, em especial alinhando os conceitos ao contexto do terceiro setor brasileiro e à relação de agência na qual o doador (principal) contrata a ONG (agente) para o desenvolvimento de projeto por meio da doação de recursos vinculados. 
O quarto artigo, escrito por Cristina Tauaf Ribeiro, tem como objeto a "Agenda em políticas públicas: a estratégia de educação financeira no Brasil à luz do modelo de múltiplos fluxos". A autora analisa a trajetória que levou ao estabelecimento da Estratégia Nacional de Educação Financeira (ENEF) no Brasil.

Em "Racionalidade substantiva e racionalidade instrumental em licitações públicas: ganhos e perdas para a seleção da proposta mais vantajosa", os autores Vanilson Viana Cardoso e Airton Adelar Mueller buscam identificar elementos nos processos licitatórios da administração pública que mantêm relação com a racionalidade instrumental e/ou substantiva.

Jeovan Assis da Silva e Tomas Aquino Guimarães promovem uma discussão articulada sobre as principais tensões entre o Poder Executivo e o Poder Judiciário em decisões inerentes à atividade regulatória, apoiada nas principais lentes teóricas e no estado da arte aplicáveis ao fenômeno, no estudo "Agências reguladoras e tribunais: inter-relações entre Administração e Justiça".

No sétimo artigo, "Estudo do engajamento do cidadão na participação de ações de mandatos eletivos no Legislativo brasileiro: análise do uso de political techs", Jessica Natalia Souza Pavan, Luis Hernan Contreras Pinochet, Gabriela de Brelàz, Durval Lucas dos Santos Júnior e Daielly Melina Nassif Mantovani Ribeiro, valendo-se de um método multivariado de equações de modelagem estrutural, com aplicação de um survey presencial em uma amostra de 467 universitários, apresentam um modelo teórico que possibilita a análise aos cidadãos no intuito de fiscalizar e participar das decisões sobre os recursos investidos em políticas e ações públicas, sendo possível, assim, fomentar o engajamento do cidadão por meio das political techs.

Em a "Influência dos sistemas de controle gerencial e da criatividade sobre o desempenho no trabalho", Itzhak David Simão Kaveski e Ilse Maria Beuren analisam a influência dos sistemas de controle gerencial (SCG) sobre o desempenho no trabalho, mediada pela criatividade individual.

Bruno Felix, na defesa de que voz e silêncio são comportamentos sociofuncionais, inseridos em interações do cotidiano no trabalho, e fundamentado na teoria da identidade social, propõe um modelo baseado em identidades sobre a voz e o silêncio de empregados, em "O Self que (não) fala: um modelo baseado em identidades sobre voz e silêncio de empregados".

Nesta linha, Julice Salvagni avança na discussão sobre identidades em "As caminhoneiras: uma carona nas discussões de gênero, trabalho e identidade". A autora aborda o trabalho por meio do entendimento das hierarquias, dos poderes e de sua divisão sexista, enfatizando a maternidade como principal entrave à continuidade da mulher na atividade de caminhoneira.

A mulher também se faz presente na pesquisa intitulada "Sistema carcerário feminino: uma análise das políticas públicas de segurança com base em um estudo local", na qual Bruna Rios Martins Santos e Vânia Aparecida Rezende sugerem que as especificidades de gênero no encarceramento feminino influenciam as vivências resultantes de vários tipos de violência que marcam definitivamente a vida das mulheres, destacando-se a relação com a maternidade, apontada como a principal fonte de sofrimento.

Dos presídios à National Football League. Que correlação podemos traçar e quais debates promover entre os dois artigos que acabamos de descrever e o estudo de Bruno Melo Moura e André Luiz Maranhão de Souza-Leão, "Identidade cultural no consumo de fãs brasileiros da National Football League"? Nesta pesquisa, os autores sugerem a existência de três categorias identitárias: nacionalismo, como forma de projetar uma imagem idealizada de nação; localismo, como demarcação das tensões das diferenças existentes no país; e minorias sociais relacionadas a gênero e orientação sexual. Revelam tensões e conformidades na construção social dessas posições. Ao apontar identidades fortemente relacionadas à noção de lugar e a representações diferentes da hétero-masculina, tais achados são evidenciados como uma versão particular dos valores centrais do próprio esporte em seu país de origem.

Acharam que o desafio das sinapses tinha acabado? Não! Se discutíssemos agora como os sujeitos, na qualidade de consumidores, mais ou menos conscientemente, conectam sua identidade a lugares para dar sentido às suas vidas? Vitor Moura Lima, Rafael Cuba Mancebo, Luís Alexandre Grubits de Paula Pessôa e Alessandra de Sá Mello da Costa desafiam-nos a apreender o processo pelo qual os consumidores fazem a ligação entre sua identidade e ambientes comerciais, baseando-se na teoria do Extended Self e perspectivas do Place Attachment.

No último artigo, "O desengajamento do trabalho artesão e os rumos da nova geração na comunidade do Alto do Moura-PE", Denise Clementino de Souza, Jessica Rani Ferreira de Sousa, Marcio Gomes de Sá e Bárbara Tayna Leal analisam as condições e os modos de desengajamento, pela nova geração, da comunidade artesã do Alto do Moura, em Pernambuco. Os autores 
investigam quais gatilhos estimulam os indivíduos a tomarem um ou outro rumo diferente ao do ofício de artesão, bem como quais as principais demandas disposicionais para mudanças na herança incorporada em sua condição de artesão.

Finalmente, na resenha bibliográfica sobre Collaborating to manage: a primer for the public sector, Agranoff, André Luis Nogueira da Silva declaram: "Não há outro caminho que não o da colaboração!"

Interessante, né?

Boa leitura!

Prof. Dr. Hélio Arthur Reis Irigaray

Editor-chefe 


\section{REFERÊNCIAS}

ABRÃO, E. Y. Direitos de autor e direitos conexos. 2. ed. rev. e ampl. São Paulo: Migalhas, 2014.

ARÉVALO, J. A. O que é plágio e como detectá-lo? Blog PPEC, Campinas, v. 4, e020001, fev. 2020. Disponível em: <https://periodicos.sbu.unicamp. br/blog/index.php/2020/02/17/arevalo/>. Acesso em: 30 jul. 2020.

BRAINY QUOTES. Wilzon Mizner Quotes. Disponível em: <https:// www.brainyquote.com/authors/wilson-mizner-quotes $>$. Acesso em: 02 ago. 2020

COSTA, R. M. C. D. Plágio acadêmico: a responsabilidade das associações Científicas. Intercom - RBCC, São Paulo, v. 39, n. 3, p. 187-200, set./dez. 2016.
LOOI, L. M.; WONG L. X,; KOH, C. C. Scientific misconduct encountered by APAME journals: an online survey. The Malaysian Journal of Pathology, v. 37, n. 3, p. 213-218, 2015.

GALVÃO, M. T. G. Plágio na construção de trabalhos científicos. Editorial. Rev Rene, v. 15, n. 2, p. 187-188, mar./abr. 2014.

GASPARYAN, A. Y. et al. The pressure to publish more and the scope of predatory publishing activities. Journal of Korean Medicinal Science, v. 31, n. 12, p. 1874-1878, 2016.

\section{Boas-vindas aos novos membros do Conselho Editorial}

Com muito orgulho e satisfação, damos as boas-vindas aos professores Gazi Islam e Russell Belk, que passam a compor nosso conselho editorial a partir deste número.

O professor Gazi Islam é aquela pessoa a quem chamamos de cidadão do mundo. De ascendência turca e naturalidade norte-americana, reside na França e fala português fluentemente. Obteve seu Ph.D. em Comportamento Organizacional na Tulane University, suas pesquisas concentram-se em identidade organizacional, voz e relações de poder.

Atualmente é professor de Administração de Empresas na Grenoble École de Management. Seus trabalhos já foram publicados em periódicos como Organization Studies, The Leadership Quarterly, Organization, Human Relations, The American Journal of Public Health, Journal of Business Ethics e American Psychologist.

Russell Belk é professor de Marketing na Schulich School of Business, da York University, em Toronto, Canadá; ocupa a Kraft Foods Canada Chair em Marketing e suas pesquisas investigam os significados de posse, possessões, coleções, presentes, compartilhamentos e materialismo, pelo olhar cultural, qualitativo e interpretativo.

Gazi e Russ, muito obrigado por terem, gentilmente, aceitado nosso convite para trabalharmos juntos! 